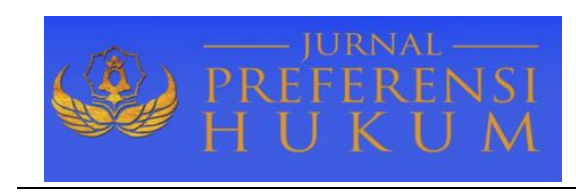

Jurnal Preferensi Hukum | ISSN: XXXX | E-ISSN: XXXX

Vol. 1, No. 2 - September 2020, Hal. 169-174| Available Online at https://www.ejournal.warmadewa.ac.id/index.php/juprehum

DOI: http://doi.org/10.22225/jph.v1i2.2355.169-174

\title{
PERANAN LEMBAGA PEMBERDAYAAN LEMBAGA PERKREDITAN DESA (LPLPD) DALAM PENYELESAIAN KREDIT MACET
}

\author{
I Wayan Sastrawan, Ida Ayu Putu Widiati, Ni Made Puspasutari Ujianti \\ Fakultas Hukum Universitas Warmadewa, Denpasar-Bali, Indonesia
}

\begin{abstract}
Abstrak
Masyarakat di Bali sangat terbantu dengan mendapatkan fasilitas kredit dari keberadaan Lembaga Perkreditan Desa (LPD). LPD merupakan urat nadi bagi keberlangsungan perekonomian suatu desa. Melihat pentingnya fungsi LPD tersebut, perlu adanya lembaga khusus yang dapat memberdayakan LPD, sehingga Lembaga Pemberdayaan Lembaga Perkreditan Desa (LPLPD) dibentuk. Kajian ini menelaah peran Lembaga Pemberdayaan Lembaga Perkreditan Desa (LPLPD) dalam penyelesaian kredit macet serta prosedur penyelesaian kredit macet di Lembaga Perkreditan Desa (LPD). Isu ini diakji dengan metode penelitian hukum normative. Dalam memberdayakan LPD, LPLPD menjalankan tugas melalui penguatan teknis terkait administrasi dan pembukuan, pengecekan, penataran, pengelolaan anggaran pengamanan LPD, pengelolaan anggaran penjaminan persediaan LPD, pengelolaan anggaran penunjang likuiditas LPD, dan pengendalian masalah-masalah LPD. LPLPD juga berupaya mencegah resiko timbulnya kredit macet di LPD melalui pembinaan yang sudah terencana dan terjadwal di masing-masing kabupaten. LPLPD melakukan tindakan preventif atau pencegahan awal dengan pembinaan teknis seperti pembinaan administrasi, pembukuan termasuk pembinaan tentang kredit. LPLPD tidak ikut menyelesaikan masalah kredit secara langsung. Sebaliknya, lembaga tersebut memberikan solusi kepada pengurus LPD untuk menganalisis permasalahan apakah dalam kredit itu yang salah adalah prosesnya atau memang nasabahnya yang tidak mampu membayar. Kalau dari teknis atau proses pemberian kredit itu yang salah, itu merupakan tanggung jawab pengelola; akan tetapi, jika prosesnya sudah benar namun nasabahnya bermasalah, prosesnya harus melalui penagihan sesuai dengan perjanjian kredit tersebut. Jika sudah terlanjur terdapat kredit macet, langkah yang harus dilakukan adalah penagihan, perbaikan dan jika itu tidak membantu maka ultimately pelelangan jaminan kredit dilakukan.
\end{abstract}

Kata Kunci: Analisis kredit; Jaminan kredit; LPD; Pembinaan teknis

\begin{abstract}
The community in Bali is greatly aided by the credit facilities with the existence of the Village Credit Institution (LPD). The institution is the lifeblood of the village's economy. Looking through the importance of the LPD's function, it is necessary to have a special institution having the power of empowering the LPD, so the Village Credit Institution Empowering Agency (LPLPD) is established. This study examines the role of the LPLPD in settling bad credit as well as the procedures for settling the bad credit at the LPD. This issue is examined by the normative legal research method. In empowering the LPD, the LPLPD performs its duties through technical strengthening related to administration and bookkeeping, checking, upgrading, LPD security budget management, LPD supply guarantee budget management, LPD liquidity support budget management, and control of LPD problems. LPLPD also seeks to prevent the risk of bad credit arising in the LPD through coaching that has been planned and scheduled in each district. LPLPD takes preventive or initial preventive action with technical guidance such as administrative guidance, bookkeeping including credit guidance. LPLPD does not participate in direct credit problem solving. On the other hand, these institutions provide solutions to LPD administrators to analyse the problem whether the credit process is due to the fault of the process or because the customer is not able to make payment. If the technical or the credit process that is wrong, it is the responsibility of the manager; however, if the process is correct but the customer causes a problem, the process must go through billing in accordance with the credit agreement. If there is already bad credit, the steps that must be taken are billing, restoration and if these are unhelpful then ultimately an credit guarantee auction is carried out.
\end{abstract}

Keywords: Credit analysis; Credit guarantee; LPD; Technical coaching 


\section{PENDAHULUAN}

Indonesia merupakan negara yang berdasarkan atas hukum, dan hal ini ditegaskan dalam hukum dasar tertulis Negara Republik Indonesia yang telah diamandemen untuk ketiga kalinya dan disahkan pada 9 November 2001. Konsekuensi Indonesia sebagai Negara Hukum adalah seluruh warga negaranya diatur dalam peraturan perundang-undangan dan harus tunduk terhadap hukum yang berlaku. Di dalam Negara Hukum tentu terdapat subyek hukum, salah satu subyek hukum adalah orang atau manusia. Manusia dalam menjalani kehidupannya memiliki kebutuhan yang harus dipenuhi seperti kebutuhan primer, sekunder, dan tersier. Dalam upaya memenuhi kebutuhan tersebut terkadang manusia dibatasi oleh kemampuan ekonomi. Untuk menunjang kemampuan ekonomi tersebut dapat dibantu dengan bantuan berupa pinjaman atau kredit.

Pinjaman atau kredit dijelaskan pada Pasal 1 Angka 11 Undang-Undang Republik Indonesia Nomor 10 Tahun 1998 yaitu tentang Perubahan atas Undang-Undang Nomor 7 Tahun 1992 tentang Perbankan, yang menjelaskan bahwa kredit atau pinjaman adalah penyediaan dana ataupun tagihan, dengan didasari kesepakatan atau dengan perjanjian saling pinjam yang dilakukan suatu bank dengan pihak debitur yang mewajibkan pihak debitur untuk membayar utang yang telah melewati waktu tertentu dengan tambahan diberikannya bunga.

Provinsi Bali memiliki lembaga khusus untuk memberikan layanan kredit yang ada di setiap desa yaitu Lembaga Perkreditan Desa (LPD). LPD mempunyai karakteristik dan desain khusus serta memiliki payung hukum Peraturan Daerah Provinsi Bali untuk beroperasi dan melakukan fungsi yang sama dengan bank dalam hal memobilisasi dana simpanan dari masyarakat dan memberikan pelayanan kredit kepada masyarakat.

Untuk mendapatkan fasilitas kredit, terlebih dahulu dilakukan perjanjian antara debitur dan kreditur. Jika perjanjian tersebut tidak dipenuhi maka terjadi wanprestasi yang mengakibatkan terjadinya permasalahan-permasalahan kredit seperti kredit macet. Bentuk dari wanprestasi dapat berupa dengan tidak melakukan yang telah disanggupi dilakukan, melakukan apa yang disanggupi tetapi tidak seperti yang dijanjikan sebelumnya, melakukan apa yang disanggupi namun terlambat, dan melaksanakan sesuatu yang tidak sesuai dengan perjanjian disepakati (Subekti, 1998).

LPD memiliki lembaga khusus untuk melakukan pemberdayaan yaitu Lembaga Pemberdayaan Lembaga Perkreditan Desa atau disebut LPLPD. Dalam menjalankan fungsinya LPLPD melaksanakan perlindungan, pembinaan dan kontrol terhadap LPD. LPLPD lebih kepada melakukan pencegahan supaya tidak terjadi permasalahan-permasalahan di LPD.

Terkait LDP kajian telah banyak dilakukan, salah satunya ialah (Kartika \& Jember, 2017) terkait sanksi adat pada LPD dalam kerangka Pirincipal-Agent LPD. Penelitian tersebut fokus pada menemukan penyebab dan sanksi serta aturan adat bagi debitur yang tidak melunasi utangnya. Kemudian, penyelesaian kredit macet dengan jaminan hak tanggungan pada LPD di Desa Padangsambian juga telah dikaji (Kariarta dkk., 2019).

Berdasarkan paparan tersebut, masalah penelitian ini dirumuskan sebagai berikut:

1. Bagaimana peran Lembaga Pemberdayaan Lembaga Perkreditan Desa (LPLPD) dalam penyelesaian kredit macet?

2. Bagaimana penyelesaian kredit macet di Lembaga Perkreditan Desa (LPD)?

Tujuan dari penelitian ini yaitu:

1. Untuk mengetahui peran Lembaga Pemberdayaan Lembaga Perkreditan Desa (LPLPD) dalam penyelesaian kredit macet.

2. Untuk mengetahui dan memahami tentang penyelesaian kredit macet di Lembaga Perkreditan Desa (LPD).

\section{METODE PENELITIAN}

Penelitian ini merupakan penelitian hukum normatif karena pengkajiannya dilakukan melalui studi kepustakaan yaitu dengan melakukan pengkajian berdasarkan bahan-bahan hukum. Sedangkan pendekatan dari masalah yang digunakan yaitu pendekatan perundang-undangan dan pendekatan seara konseptual.

Adapun sumber bahan hukum yang dipergunakan yaitu:

1. Bahan Hukum Primer 
Bahan hukum primer yang dipergunakan berupa peraturan perundang- undangan, yaitu: Kitab Undang-Undang Hukum Perdata, Undang-Undang Nomor 10 Tahun 1998 tentang Perubahan Atas Undang-Undang Nomor 7 tahun 1992 tentang Perbankan, Undang-Undang Nomor 1 Tahun 2013 tentang Lembaga Keuangan Mikro, Undang-Undang Nomor 23 tahun 2014 tentang Pemerintahan Daerah, Peraturan Daerah Provinsi Bali Nomor 3 Tahun 2017 tentang Lembaga Perkreditan Desa, Peraturan Gubernur Bali Nomor 44 tahun 2017 tentang Peraturan Pelaksanaan Peraturan Daerah Provinsi Bali Nomor 3 Tahun 2017 tentang Lembaga Perkreditan Desa, dan Peraturan Daerah Provinsi Bali Nomor 4 tahun 2019 tentang Desa Adat Di Bali.

2. Bahan Hukum Sekunder

Bahan hukum sekunder yaitu berpedoman pada sumber ilmiah, artikel- artikel, jurnal hukum dan yang lain terkait dengan Lembaga Perkreditan Desa.

Adapun teknik pengumpulan bahan hukum primer dan bahan hukum sekunder dengan melakukan teknik pencatatan yaitu dengan melakukan inventarisasi bahan hukum, klasifikasi atau pemilahan, metode pengutipan dan peringkasan.

\section{HASIL DAN PEMBAHASAN}

\section{Peranan Lembaga Pemberdayaan Lembaga Perkreditan Desa (LPLPD) dalam Penyelesaian Kredit Macet}

Ketika memberikan pinjaman atau kredit, lembaga perbankan maupun lembaga non perbankan lainnya sebagai kreditur harus memiliki suatu keyakinan terhadap kesediaan dari nasabah atau debitur apakah mampu untuk melunasi pinjamannya sesuai dengan perjanjian. Untuk memperoleh keyakinan tersebut maka sebelum dilaksanakan perjanjian kredit, bank atau lembaga-lembaga perkreditan harus melakukan penilaian dengan seksama baik itu terhadap karakter, kemampuan, maupun prospek usaha dari debitur. Perjanjian kredit adalah perjanjian yang meminjamkan uang dengan bunga atau tanpa bunga, ataupun suatu barang tertentu yang wajib dikembalikan sesuai nilainya masing- masing pada saat waktu yang telah disepakati (Soekanto \& Taneko, 1981).

Adapun tujuan dari memberikan pinjaman atau kredit adalah untuk memberikan bantuan kepada nasabah jika membutuhkan modal, berupa uang untuk melakukan kegiatan usaha atau sebagai modal pekerjaan sampai nasabah bisa membesarkan usaha yang dilakukannya. Jika bank maupun lembaga- lembaga perkreditan tidak memperhatikan prinsip-prinsip pemberian kredit dalam memberikan kredit kepada nasabah, maka akan dikhawatirkan munculnya suatu permasalahan kredit. Salah satu diantara permasalahan kredit tersebut adalah kredit macet.

Sebelum diberikannya kredit, untuk meyakinkan kepada bank bahwa nasabah atau debitur tersebut benar bisa dipercayai, maka terlebih dahulu bank melakukan analisis terhadap kredit. Analisis kredit ini tentang latar belakang dari nasabah ataupun perusahaan, bagaimana prospek dari usahanya, apa jaminan yang dapat diberikan serta faktor lainnya. Tujuan dari analisis ini supaya bank mempunyai keyakinan bahwa pinjaman atau kredit yang nantinya diberikan benar-benar aman (Kasmir, 2001).

Dalam dunia perbankan, kredit yang macet dikenal dengan sebutan Non- Performing Loan (NPL). NPL merupakan indikator untuk menilai bagaimana performa bank. Kalau NPL suatu bank rendah, bank tersebut dapat dikatakan kondisinya sehat. Namun jika NPL tinggi, maka resiko yang dialami oleh bank tersebut juga tinggi. Jikalau NPL bank diatas batas yang telah diforecast sebelumnya maka bank tersebut dapat dibilang bermasalah. Kredit macet merupakan keadaan ketika nasabah atau debitur baik itu perorangan ataupun perusahaan tidak bisa melunasi kredit atau pinjaman sesuai dengan jangka waktu yang telah ditentukan sebelumnya. Kegagalan suatu kredit bisa berasal dari dalam bank atau dari pihak diluar bank itu sendiri (Suharno \& Soeharsono, 2003).

Penyebab terjadinya kredit atau pinjaman yang macet di Lembaga Perkreditan Desa (LPD) juga disebabkan karena berbagai keadaan. Menurut hasil wawancara dengan Bapak I Nyoman Cendikiawan selaku Ketua Badan Kerjasama Lembaga Perkreditan Desa (BKS-LPD) Provinsi Bali pada tanggal 6 Juli 2019, salah satu yang menjadi penyebab terjadinya kredit macet di LPD karena usaha nasabah atau debitur yang bangkrut. Macetnya suatu kredit memang disebabkan karena debitur bukan dikarenakan pihak dari LPD. Debitur mencari kredit diperuntukan membantu usahanya agar berjalan dengan lancar, namun usaha yang dilakukan terjadi kebangkrutan yang mengakibatkan sisa hutangnya tidak dapat dilunasi. 
Sesuai dengan nama dari LPLPD yaitu Lembaga Pemberdayaan Lembaga Perkreditan Desa, tujuan dari LPLPD ialah untuk melakukan pemberdayaan terhadap LPD. Kegiatan pemberdayaan yang dilakukan LPLPD dijelaskan di Peraturan Gubernur Bali Tahun 44 Tahun 2017 tentang Peraturan Pelaksanaan Peraturan Daerah Provinsi Bali Nomor 3 Tahun 2017 tentang Lembaga Perkreditan Desa, pasal 58 ayat (1). LPLPD memiliki tugas untuk melakukan pemberdayaan terhadap LPD dengan kegiatan penguatan teknis terkait administrasi, pembukuan, kredit dan lainnya, melakukan pengecekan atau audit, penataran-penataran, pengelolaan anggaran perlindungan LPD, pengelolaan anggaran penjaminan simpanan LPD, pengelolaan anggaran penopang likuiditas LPD, serta pengendalian masalah yang terjadi di LPD.

\section{Penyelesaian Kredit Macet di Lembaga Perkreditan Desa (LPD)}

Untuk menangani kredit macet LPLPD tidak ikut menyelesaikan permasalahan kredit tersebut. Namun LPLPD berperan untuk menganalisis apakah dalam kredit itu prosesnya yang salah atau memang nasabahnya yang tidak mampu membayar. Kalau dari teknis atau proses pemberian kredit itu yang salah maka itu merupakan tanggung jawab pengelola. Tapi kalau sebaliknya prosesnya sudah benar namun nasabahnya yang bermasalah maka prosesnya harus ditagih sesuai dengan perjanjian kredit tersebut. Langkah-langkahnya adalah pertama ada penagihan, kedua perbaikan, jika itu tidak bisa maka terakhir dilakukan pelelangan jaminannya.

Jaminan atau agunan kredit oleh debitur diharapkan bisa membantu melancarkan pemberian dari kredit tersebut, dengan demikian maka jaminan kredit haruslah:

1. Secured, diartikan bahwa jaminan atau agunan kredit tersebut dapat dibuatkan pengikatannya secara yuridis formal, yang sesuai dengan ketentuan hukum dan undang-undang yang berlaku. Sehingga jika nantinya terdapat wanprestasi dari debitur, maka bank telah memiliki alat bukti yang lengkap untuk melakukan tindakan hukum.

2. Marketable, diartikan apabila jaminan atau agunan tersebut memang dapat, perlu, dan harus untuk dieksekusi, maka jaminan atau agunan kredit tersebut bisa dengan mudah dijual atau bisa diuangkan untuk segera digunakan melunasi hutangnya (Hasanuddin, 1998).

Menurut Bapak I Nyoman Arnaya selaku Kepala Lembaga Pemberdayaan Lembaga Perkreditan Desa (LPLPD) Provinsi Bali ketika diwawancarai pada tanggal 22 Juli 2019, untuk mengurangi resiko kredit macet ini dilakukan terlebih dahulu pencegahan awal dengan dilaksanakan pembinaan teknis. Kegiatan pembinaan teknis ini dilakukan dengan pelatihan-pelatihan sistem administrasi LPD, pelatihan pembukuan, termasuk pelatihan tentang kredit itu sendiri yang sudah terencana dan terjadwal setiap bulan di masing-masing Kabupaten.

Berdasarkan informasi dari Bapak Gusti Agung Bagus Budiarsa selaku Wakil Koordinator Lembaga Pemberdayaan Lembaga Perkreditan Desa (LPLPD) Kabupaten Tabanan ketika diwawancarai pada tanggal 22 Juli 2019, terkait kredit macet di Kabupaten Tabanan, dari 307 LPD disetiap LPD tentu punya kredit macet. Hanya saja jika misal macetnya 0,2\% atau dibawah 5\% kondisi tersebut masih dikatakan sehat. Jika kredit macet diatas 5\% baru dilaksanakan pembinaan yang intensif.

Menurut Bapak Gusti Agung Bagus Budiarsa, di Kabupaten Tabanan sendiri yang saat ini memiliki kredit macet diatas 5\% adalah LPD Batungsel dan LPD Blungbang. Sehingga sering dilakukan monitoring dan turun kelapangan untuk memberikan pembinaan kepada LPD tersebut. Solusi yang dapat diberikan dari LPLPD Tabanan terkait permasalahan kredit macet adalah pertama dengan mengirim SP (Surat Pemberitahuan) kredit macet, kedua tetap menyarankan pembinaan kredit macet lebih ditingkatkan, ketiga apakah di restrukturisasi atau di rescheduling artinya diulang kredit tersebut, dan terakhir dengan senjata pamungkas dengan menerapkan aturan perarem di desa masingmasing.

Bapak Gusti Agung Bagus Budiarsa juga menjelaskan keunggulan LPD adalah bisa menggunakan perarem di desa. Dengan perarem tersebut besar kemungkinan permasalahan kredit macet bisa diselesaikan. Penyebab kredit macet di Kabupaten Tabanan adalah karena nakal (karakter), kondisi ekonomi yang kurang, dan karena nasabah banyak di sektor pertanian kalau belum musim buah di gunung misalnya maka kreditnya akan macet. Maka dari itu selain melakukan pembinaan, terpaksa dengan menunggu hasil panen buah dengan menjadwalkan ulang kredit tersebut (rescheduling). Maksudnya dapat dengan memperpanjang waktu kredit tersebut. 
Sementara di LPD Blungbang sendiri sampai saat ini belum bisa beroperasi dikarenakan kredit macet terjadi karena pengurus LPD tersebut yang nakal memakai kredit tersebut. Sehingga dari desa menunggu penjualan aset atau jaminan. Sedangkan untuk menjual aset sekarang dikatakan cukup sulit.

Berbagai permasalahan-permasalahan kredit macet yang terdapat di masing-masing LPD tentu harus diselesaikan dengan solusi atau jalan keluar yang tepat. Pembinaan-pembinaan teknis dari LPLPD mengenai administrasi, pembukuan dan tekait pembinaan kredit tentu menjadi kunci dalam penanganan kredit macet di LPD.

Dengan tindakan preventif atau pencegahan tersebut, resiko kredit macet yang terjadi kemungkinan lebih sedikit ditemui di masing-masing LPD. Selain dapat melakukan analisis yang tepat jika terlanjur sudah ditemui kredit yang macet. Sehingga harapan kedepan LPD dapat terus eksis sebagai lembaga keuangan pedesaan di Provinsi Bali. Yang secara historis telah dicetuskan oleh Gubernur Bali ke 5 Prof. Dr. Ida Bagus Mantra pada tahun 1984.

\section{SIMPULAN DAN SARAN}

\section{Simpulan}

Dari pembahasan diatas, penulis menarik beberapa simpulan yaitu:

1. Dari sudut kolektibilitas, kredit digolongkan dalam keadaan yang lancar, kurang lancar, kredit diragukan, dan kredit macet. Setiap lembaga perbankan ataupun lembaga keuangan non-bank pasti akan mengalami kredit macet. Di LPD kredit macet lebih sering terjadi karena disebabkan memang dari debitur. Untuk menyelesaikan kredit macet di LPD, terlebih dulu diberikan Surat Pemberitahuan (SP) secara bertahap. Jika permasalahan berlanjut maka langkah yang diambil adalah pengambilan alihan agunan atau jaminan kredit. Ketentuan pengambil alihan agunan ini didasarkan pada keputusan dalam paruman desa yang dilaksanakan oleh pengurus LPD dan pengawas intern LPD yaitu Bendesa dan Prajuru Desa. Selain itu juga dapat mengundang LPLPD untuk memberikan solusi.

2. LPLPD merupakan sebuah lembaga khusus dengan tugasnya yaitu untuk memberdayakan LPD. Dalam menangani kredit macet, LPLPD melakukan tindakan preventif atau pencegahan awal dengan pembinaan teknis. LPLPD tidak ikut menyelesaikan masalah kredit secara langsung. Namun memberikan solusi kepada pengurus LPD dengan analisis permasalahan kredit tersebut. LPLPD berperan untuk menganalisis apakah dalam kredit itu prosesnya yang salah atau memang nasabahnya yang tidak mampu membayar. Langkah-langkah yang diambil adalah pertama dengan adanya upaya penagihan, langkah kedua perbaikan, dan jika itu tidak bisa maka terakhir dilakukan pelelangan.

\section{Saran}

1. Diharapkan kepada bagian kredit di LPD untuk melakukan analisis secara seksama sesuai dengan prinsip 5C sebelum pencairan kredit dan dalam mencari kredit debitur harus mengajak keluarga sebagai penanggungnya.

2. Diharapkan kepada LPD agar mencarikan jalan keluar seperti menjual bersama-sama jaminan dari debitur yang memiliki tanda-tanda tidak mampu membayar.

3. Diharapkan kepada LPLPD untuk memberikan evaluasi kepada LPD yang mengalami kredit macet agar tidak terjadi kesalahan berulang. Dan secara kuratif dapat memberikan pembinaan kredit yang intensif dan berkelanjutan.

\section{DAFTAR PUSTAKA}

Hasanuddin, R. (1998). Aspek-Aspek Hukum Pemberian Kredit Perbankan di Indonesia (Panduan Dasar: Legal Officer). PT. Citra Aditya Bakti.

Kariarta, K. W., Udiana, I. M., \& Purwanto, I. W. N. (2019). Penyelesaian Kredit Macet pada Lembaga Perkreditan Desa di Desa Padangsambian Kota Denpasar. E-Jurnal Akuntansi Univeristas Udayana, 1, 1-476.

Kartika, I. N., \& Jember, I. M. (2017). Sanksi Adat Pada Lembaga Perkreditan Desa Dalam Kerangka Principal-Agent LPD (Lembaga Perkriditan Desa) Se-Kecamatan Tembuku Kabupaten Bangli. Jurnal Ekonomi Kuantitatif Terapan, 10(2), 183-191.

Kasmir. (2001). Bank \& Lembaga Keuangan Lainnya. PT. Raja Grafindo Persada. 
Soekanto, S., \& Taneko, S. B. (1981). Hukum Adat Indonesia. Rajawali.

Subekti. (1998). Hukum Perjanjian. Intermasa.

Suharno, \& Soeharsono. (2003). Analisa Kredit. Djambatan. 